\title{
RESUMEN DE LA ACTIVIDAD DEL TRIBUNAL CONSTITUCIONAL DEL SEGUNDO CUATRIMESTRE DE 1999
}

\author{
LUCRECIO REBOLLO DELGADO \\ Profesor Asociado de Derecho Constitucional \\ UNED
}


. 


\title{
RESUMEN DE ACTIVIDAD DEL TRIBUNAL CONSTITUCIONAL DEL SEGUNDO CUATRIMESTRE DE 1999
}

\author{
POR \\ LUCRECIO REBOLLO DELGADO \\ Profesor Asociado de Derecho Constitucional \\ UNED
}

El Tribunal Constitucional ha dictado durante este periodo un total de 68 sentencias distribuidas de la forma que refleja el presente cuadro:

\begin{tabular}{lcccc}
\hline & $\begin{array}{c}\text { Recursos } \\
\text { de amparo }\end{array}$ & $\begin{array}{c}\text { Recursos de } \\
\text { inconstituc. }\end{array}$ & Cuestiones & Conflictos \\
\hline Sentencias & 61 & 3 & 3 & 1 \\
\hline
\end{tabular}

Como es costumbre en esta sección de la revista, agrupamos el número de recursos de amparo atendiendo al derecho que se dilucida o que es parte central del argumento del Tribunal. 


\section{RECURSOS DE AMPARO}

Principio de igualdad

- STC 102/99 de 31 de junio

- STC 123/99 de 28 de junio

Derecho a la intimidad personal y familiar

- STC 94/99 de 31 de mayo

- STC 95/99 de 31 de mayo ${ }^{1}$

- STC 139/99 de 22 de junio

- STC 144/99 de 22 de junio

\section{Libertad de expresión e información}

- STC $59 / 99$ de 26 de mayo

\section{Derecho al honor}

- STC 134/99 de 15 de julio

\section{Derecho de asociación}

- STC 104/99 de 14 de junio

Derecho de acceso en condiciones de igualdad a cargo público

- STC $87 / 88$ de 25 de mayo

- STC 93/99 de 27 de mayo

- STC 146/99 de 27 de julio

- STC 148/99 de 4 de agosto

1 Se analiza esta sentencia en el apartado de Resumen de Doctrina. 
- STC 149/99 de 4 de agosto

- STC 99/99 de 31 de mayo

Principio de legalidad penal

- STC 136/99 de 20 de julio

- STC 142/99 de 22 de julio

\section{Libertad sindical}

- STC 145/99 de 22 de julio

\section{Tutela judicial efectiva}

1. Deficiencias procesales

- STC $81 / 99$ de 10 de mayo

- STC $89 / 99$ de 26 de mayo

- STC 92/99 de 26 de mayo

- STC 105/99 de 14 de junio

- STC 106/99 de 14 de junio

- STC $107 / 99$ de 14 de junio

- STC 108/99 de 14 de junio

- STC $109 / 99$ de 14 de junio

- STC $110 / 99$ de 14 de junio

- STC $112 / 99$ de 14 de junio

- STC $117 / 99$ de 28 de junio

- STC $137 / 99$ de 22 de junio

- STC 141/99 de 22 de julio

- STC 147/99 de 4 de agosto 
2. Presunción de inocencia

- STC 86/99 de 10 de mayo

— STC 91/99 de 26 de mayo

- STC 97/99 de 31 de mayo

- STC 111/99 de 14 de junio

3. Incongruencia en la resolución judicial o error en la sentencia

- STC 96/99 de 31 de mayo

- STC 113/99 de 14 de junio

- STC 132/99 de 15 de julio

- STC 133/99 de 15 de julio

4. Sentencia dictada inaudita parte

- STC 88/99 de 26 de mayo

- STC 98/99 de 31 de mayo

- STC $119 / 99$ de 28 de junio

- STC 138/99 de 22 de julio

5. Acceso a la jurisdicción

- STC 115/99 de 14 de junio

- STC $135 / 99$ de 15 de julio

6. Derecho a un proceso sin dilaciones indebidas

- STC $124 / 99$ de 28 de junio

- STC $125 / 99$ de 28 de junio 
7. Tutela judicial e igualdad ante la ley

- STC $84 / 99$ de 10 de mayo

8. Inadmisión del recurso

- STC 100/99 de 31 de mayo

- STC 121/99 de 28 de junio

- STC 122/99 de 28 de junio

9. Derecho a la utilización de pruebas y valoración

- STC 85/99 de 10 de mayo

- STC 101/99 de 31 de mayo

- STC 120/99 de 28 de junio

- STC 140/99 de 22 de julio

10. Indefensión

- STC $82 / 99$ de 10 de mayo

- STC 83/99 de 10 de mayo

- STC 118/99 de 28 de junio

- STC 126/99 de 28 de junio

11. Sentencia lesiva de derechos

- STC 106/99 de 14 de junio

\section{RECURSOS DE INCONSTITUCIONALIDAD}

- STC 103/99 de 3 de junio. Solventa esta sentencia los recursos acumulados promovidos por el Parlamento de Cataluña y el Gobierno vasco, contra determinados artículos de la Ley 32/1988, de 10 de noviembre (Ley de Marcas). La pretensión de los recursos es evitar la 
existencia de un Registro único de Marcas dependiente de la Administración General del Estado. El Tribunal argumenta la constitucionalidad de la existencia de un único registro debido a la indivisibilidad de la materia, a la vez que reconoce la lesividad constitucional de determinadas competencias de ejecución, en virtud de lo cual establece la competencia de las Comunidades Autónomas recurrentes en materia de ejecución relativa a la propiedad industrial.

- STC 116/99 de 17 de junio2. El recurso es promovido por más de cincuenta diputados del Grupo Parlamentario Popular contra la Ley 35/1988 de 22 de noviembre (Ley de Técnicas de la Reproducción Asistida). Se argumenta por los recurrentes la inconstitucionalidad total de la ley, debido a que con su vigencia pueden reconocerse modalidades de aborto distintas a las establecidas en la actualidad. Además argumentan los recurrentes el tipo legislativo utilizado (ley ordinaria), pues a su entender y tratándose de un derecho fundamental, la norma debería ser orgánica en virtud del art. $81 \mathrm{CE}$. El fallo reiterpreta algunos artículos (inciso final del art. 12.2 de la Ley, y declara la nulidad constitucional del inciso inicial del art. 20.1. Se formula voto particular discrepante del magistrado Jiménez de Parga, al que se adhiere el magistrado Garrido Falla, por estimar que la Ley de Técnicas de Reproducción Asistida habría de tener el carácter de orgánica.

- STC 127/1999 de 1 de julio. Solventa el recurso promovido por el Presidente del Gobierno contra el art. 10 y la Disposición Adicional tercera de la Ley de la comunidad de Galicia, Ley 13/1989 de Montes Vecinales en Mano Común. La sentencia estima el recurso en su totalidad, basándose en el principio de que las especialidades normativas de la citada comunidad autónoma no pueden en ningún caso modificar o alterar las normas procesales comunes.

\section{CUESTIONES DE INCONSTITUCIONALIDAD}

- STC 129/1999 de 1 de julio. Resuelve la cuestión planteada por un Juzgado de 1.a Instancia en relación al art. 211, apartado segundo del Código Civil (redacción dada por Ley 13/83 de 24 de octubre). El objeto de la cuestión es el alcance de la tutela. El Tribunal entiende

2 Se hace comentario más extenso de esta sentencia en el apartado de Resumen de Doctrina. 
que el artículo citado no es inconstitucional, y que ha de interpretarse en conjunción con los artículos 1.811 a 1.824 de la Ley de Enjuiciamiento Civil. El magistrado García Manzano formula voto particular discrepante por entender que la norma objeto de recurso debería tener carácter de orgánica, dado que afecta a la libertad personal.

- STC 130/1999 de 1 de julio. El objeto de la cuestión planteada por el Tribunal Superior de Cantabria es la Disposición Adicional octava de la Ley de la Comunidad Autónoma de Cantabria de Presupuestos Generales de la Diputación Regional de Cantabria para 1993. Se declara la nulidad de la disposición objeto de cuestión, debido a la improcedencia del tipo normativo usado. A juicio del Tribunal es una norma de nítido "contenido funcionarial" incluida dentro de una norma de tipo presupuestario.

- STC 131/1999 de 1 de julio. El conflicto lo plantea del Tribunal Superior de Canarias en relación a la Disposición Adicional 5. a de la Ley 31/1999 de 30 de diciembre (Ley de Presupuestos Generales del Estado para 1992), por entender contradicción con el art. 134.2 de la Constitución. Se desestima la cuestión, y estima justificada la inclusión del precepto controvertido en Ley de Presupuestos. Acude para ello a su propia jurisprudencia (STC 203/98, f. J. $5 .^{\circ}$ ).

\section{CONFLICTOS DE COMPETENCIA}

- STC 128/1999 de 1 de julio. El conflicto es promovido por la Diputación Regional de Cantabria en relación a varios artículos del Real Decreto $1.887 / 91$ de 30 de diciembre, relativo a la mejora de estructuras agrarias. El objeto de controversia son las subvenciones agrarias, con conexión a la normativa de la Unión Europea. El fallo es parcialmente estimatorio, pero no declara la inconstitucionalidad de los preceptos objeto de conflicto.

\section{RESUMEN DE DOCTRINA}

\section{STC 95/1999 de 31 de mayo (BOE 29-6-99 n. ${ }^{\circ} 154$ suplemento)}

Resuelve en esta sentencia el Tribunal el recurso de amparo formulado contra auto de la Sala Primera del Tribunal Supremo, sustanciándose un procedimiento de filiación extramatrimonial. 
En 1991 D. Enrique Dafonte presentó en primera instancia juicio de menor cuantía con objeto de que se declarara a la hija de la demandada (Genoveva Ribera) como suya, y por tanto que lleve sus apellidos y se le otorgue el oportuno régimen de comunicación y visitas con la menor, a la vez que solicita la constancia en el Registro Civil de la paternidad. La primera instancia estima en todo las pretensiones del demandante. Dña. Genoveva Ribera presentó recurso ante la Audiencia Provincial de Cádiz, la que dictó sentencia confirmando todos los pronunciamientos de la primera instancia. La demandada interpone recurso de casación ante el Tribunal Supremo, el cual mediante auto lo inadmite por falta de fundamento jurídico. Con posterioridad se interpone recurso de amparo, en la idea de que ha sido vulnerado su derecho a la intimidad personal y familiar y el derecho a la tutela judicial efectiva. Alega la recurrente que "jamás mantuvo relaciones sexuales de ningún tipo con $\mathrm{D}$. Enrique Lafonte, por lo que es absolutamente imposible que éste sea el padre de su hija".

Es importante destacar que se había solicitado por parte de D. Enrique Lafonte la realización de la prueba biológica de paternidad, la cual no pudo realizarse por no comparecer a la misma la madre y la hija. La recurrente en amparo argumenta que no ha resultado probada la relación sexual entre ambos litigantes, lo que la exoneraba de someterse a la prueba biológica.

El Tribunal recuerda la cobertura legal del sometimiento a la prueba biológica para determinar la paternidad, que se fundamenta en el art. 127 del Código Civil y en el art. 39.3 CE, en virtud de los cuales no se lesiona el derecho a la integridad física y el derecho a la intimidad del afectado. Recuerda además, "que las partes tienen la obligación de posibilitar la práctica de las pruebas biológicas que hayan sido debidamente acordadas por la autoridad judicial, por ser este un medio de prueba esencial". Además recuerda el Tribunal, que es doctrina sentada que "cuando un órgano judicial, valorando la negativa del interesado a someterse a las pruebas biológicas, en conjunción con el resto de los elementos fáctivos acreditados a lo largo del procedimiento, llega a la conclusión de que existe la relación de paternidad negada por quien no posibilitó la práctica de la prueba biológica, nos hallamos ante un supuesto de determinación de la filiación, permitido por el art. 135 del Código Civil». En base a lo manifestado el Tribunal estima denegar el amparo solicitado.

De la sentencia se pueden extraer al menos dos conclusiones significativas. Quizás la más llamativa sea la desviación del fundamento de las resoluciones judiciales de todas las instancias por la que pasa el 
proceso, incluida la constitucional, de no hacer recaer la prueba determinante en la constatación de la relación sexual entre demandante y demandada, y sí por contra tener en cuenta el contexto y todas las circunstancias colindantes a él, y que resultaron probadas. De esta forma se ratifica la prevalencia del art. 39.2 sobre los derechos a la dignidad, integridad física, honor, intimidad y tutela judicial efectiva de la demandante en amparo.

Otra conclusión significativa es para todas las instancias, la importancia dada a la prueba hematológica para determinar la paternidad. El Tribunal Constitucional ratifica la esencialidad de este medio probatorio, del que manifiesta que es «fiable e idóneo para la determinación del hecho de la generación discutido en el pleito, pues en estos casos, al hallarse la fuente de la prueba en poder de una de las partes en litigio, la obligación constitucional de colaborar con los Tribunales en el curso de un proceso (art. $118 \mathrm{CE}$ ), conlleva que dicha parte deba contribuir con su actividad probatoria a la aportación de los hechos referidos...". Esta circunstancia es determinante a juicio del Tribunal dado que coloca al otro litigante en una situación de indefensión.

\section{STC 116/1999 de 17 de junio (BOE 17-6-99 n. ${ }^{\circ} 162$ suplemento)}

Es ésta una Sentencia significativa, sobre todo, por la interpretación constitucional que realiza de las técnicas de reproducción asistida, a la vez que aporta también conclusiones capitales relativas al art. $81 \mathrm{CE}$.

Resuelve la Sentencia el recurso de inconstitucionalidad promovido con fecha 27 de febrero de 1989, por D. Federico Trillo-Figueroa, comisionado por 63 diputados del Grupo Parlamentario Popular, contra la totalidad de la Ley de Técnicas de Reproducción Asistida (Ley $35 / 1988$ de 22 de noviembre) y subsidiariamente contra abundante contenidos de la misma, incluida la exposición de motivos.

Pueden resumirse los fundamentos del recurso en tres motivos esenciales:

1. De los artículos $1,9.3,10.1,15,18,27,32,33.1,35$ y 39 de la CE deducen un concepto de familia, que entienden vulnerado por los artículos $1.1,5.1$ y $5,6.1$ y 7 a 10 de la Ley recurrida en inconstitucionalidad.

2. Como segundo motivo de inconstitucionalidad alegan los recurrentes la vulneración del art. 15 de la $C E$, pues a su juicio no está configurado un status jurídico de los embriones. 
3. Como último fundamento del recurso, tachan los recurrentes a la ley de inconstitucionalidad, por infracción del art. 81.1 CE, dado que la norma recurrida carece de carácter de orgánica, y debería tenerlo dado que afecta al desarrollo de los derechos fundamentales de la persona.

Entiende el Tribunal que esta última alegación, de ser estimada pudiera dar lugar a una declaración de inconstitucionalidad de toda la ley, "por lo que ha de ser examinado con carácter previo y singularizado". Además pretende organizar las cuestiones debatidas y dar un orden distinto a los argumentos del recurso. A juicio del Tribunal, es preferible ir en su resolución de lo genérico a lo concreto; nosotros seguimos este orden para una mejor comprensión de la sentencia que estudiamos.

La primera manifestación significativa del Tribunal la constituye la improcedencia de solicitar la inconstitucionalidad de un párrafo de la Exposición de Motivos de la ley, dado que como ha dejado ya sentado en su jurisprudencia, ésta parte de las leyes carecen de valor normativo por lo que no pueden ser objeto directo de recurso de inconstitucionalidad. Tampoco serán objeto de enjuiciamiento los artículos expresamente derogados por el Código Penal de 1995.

Analiza con posterioridad el Tribunal la necesidad de haber utilizado ley orgánica en la regulación de las técnicas de reproducción asistida, y lo hace de forma escueta y a nuestro juicio sesgando el contenido constitucional. El principal argumento del TC para justificar el uso de ley ordinaria lo constituye el que requieren este tipo de ley "los derechos y libertades públicas regulados en la sección primera del Capítulo Segundo del Título I, entre los que, obviamente, no se encuentra la dignidad de la persona, que, además es reconocida en nuestra Constitución como fundamento del orden político y de la paz social (art. 10.1 CE)". Continúa afirmando la sentencia que si el art. 15 $\mathrm{CE}$ ureconoce como derecho fundamental el derecho de todos a la vida, derecho fundamental del que, como tal y con arreglo a la STC $53 / 1985$, son titulares los nacidos, sin que quepa extender esa titularidad a los nacituri (STC 212/1996, f. j. 3a), es claro que la ley impugnada, en la que se regulan técnicas reproductoras referidas a momentos previos al de la formación del embrión humano, no desarrolla el derecho fundamental a la vida reconocida en el art. $15 \mathrm{CE}$. Por consiguiente, la Ley 35/1988 no vulnera la reserva de Ley Orgánica exigida en el art. 81.1 CE».

A esta afirmación se opone en voto particular el magistrado Jiménez de Parga al que presta su adhesión el Magistrado Garrido Falla. 
En aquél se manifiesta que «la ley recurrida es, a mi entender inconstitucional» por las siguientes razones:

1. La dignidad de la persona es un valor jurídico fundamental, vertebra el ordenamiento jurídico y es fundamento del orden político y de la paz social.

2. La reserva del art. 81 de la $\mathrm{CE}$, tiene a juicio de los magistrados que formulan el voto particular carácter material y no formal, "de manera que la normación de las materias ajenas a las mismas no gozan definitivamente de la fuerza pasiva inherente a dicha clase de leyes aunque se incluyan en ellas". Además la reserva que estudiamos no se establece constitucionalmente como abierta, pero tampoco como cerrada, dado que se reconoce implícitamente al legislador la facultad de precisar las materias conexas a la reserva, de lo que se concluye a juicio del magistrado discrepante que "cuanto sea inherente a un derecho fundamental, con protección reforzada, ha de ser regulado por Ley Orgánica".

A nuestro juicio es aquí donde radica el error de la sentencia. Realizar una interpretación de la reserva del art. 81 CE desde una perspectiva formal, significa romper la pretensión del constituyente de configurar un ordenamiento social en base a unos valores, unos principios y unos fundamentos. La dignidad humana requiere de una concreción y esta se realiza a través de derechos, primero a través de los que gozan de una mayor protección (derechos fundamentales) y en un segundo plano a través de otros derechos constitucionales. Aplicar el criterio de reserva tomando como elemento delimitador la estricta letra de la Constitución y no ampliarlo, como es el caso que nos ocupa a su fundamento, nos parece constitucionalmente improcedente. Concluimos en suma que la regulación de las técnicas de reproducción asistida habrían de ser reguladas por ley orgánica. A favor de este argumento juega también en este asunto la necesidad de un respaldo político mayoritario en una cuestión tan capital y de tanta repercusión social como son las técnicas de reproducción asistida. Este se consigue con un tipo normativo que la Constitución específicamente configura, como es la ley orgánica.

Rechazada por parte del Tribunal la impugnación dirigida a la totalidad de la ley y establecida la no vulneración del art. 15 CE por parte de la Ley recurrida, se enjuicia la constitucionalidad de los preceptos concretos antes referidos (arts. 1, apartado 4, en relación con los arts. 
14 a 17 de la propia ley; 2 , apartado $4 ; 5$, apartado $1 ; 11$, apartados 3 y $4 ; 12.1 ; 13 ; 14$, apartados 1 y $4 ; 15 ; 16$, apartados 1 y 2 y 17 ).

En lo referente a los artículos 1 y 14 a 17 manifiesta el Tribunal que han de ser enjuiciados desde la perspectiva del art. 44.2 CE según el cual «los poderes públicos promoverán la ciencia y la investigación científica y técnicá en beneficio del interés general». A juicio del Tribunal no es función suya establecer criterio o límites a la normativa, entendiendo a su vez la constitucionalidad de dichos artículos. Concluye manifestando «que sólo forzando el sentido de los términos pueden alcanzarse la conclusión de que la investigación o experimentación sobre o con los gametos pueda suponer atentado alguno al derecho a la vidan. El mismo criterio debe aplicarse al art. 15.1 de la ley recurrida.

Tampoco aprecia inconstitucionalidad el Tribunal en los artículos $4 ; 11.3$ y 4 y art. 5.1. dado que la ucrioconservación no sólo no resulta atentatoria a la dignidad humana, sino que, por el contrario y atendiendo al estado actual de la técnica, se nos presenta más bien como el único remedio para mejor utilizar los preembriones ya existentes, $y$ evitar así fecundaciones innecesarias".

Por lo que respecta a los artículos 12 y 13 que prevén determinadas intervenciones orientadas a fines de diagnóstico o terapéutico, entiende el Tribunal que en lo referido al art. 13 (intervenciones con fines terapéuticos en preembriones, embriones y fetos) la norma es clara $y$ no puede deducirse inconstitucionalidad de su letra. El art. 12 en su apartado segundo autoriza intervenciones con finalidad diagnóstica "sobre el embrión o sobre el feto, en el útero o fuera de él, vivos", siempre que tengan por objeto "el bienestar del nasciturus y el favorecimiento de su desarrollo, o si está amparada legalmente». A juicio del Tribunal el inciso final del art. 12.2 "o si está amparada legalmente", sólo es constitucional interpretado en el sentido de que las intervenciones amparadas legalmente son las comprendidas en el art. 417 del Código Penal. 